OPEN ACCESS

Edited by:

Lingzhan Miao,

Hohai University, China

Reviewed by:

Nsikak U. Benson,

Covenant University, Nigeria

*Correspondence:

Jun Sun

phytoplankton@163.com

Specialty section:

This article was submitted to

Marine Pollution,

a section of the journal

Frontiers in Marine Science

Received: 19 October 2021 Accepted: 25 November 2021 Published: 22 December 2021

Citation:

Noman MA, Sun J and Hossain MB (2021) COVID-19

Generated Personal Protective

Equipment: Sources of Microplastics and Pathogen Vectors in Marine

Environments?

Front. Mar. Sci. 8:798047. doi: 10.3389/fmars.2021.798047

\section{COVID-19 Generated Personal Protective Equipment: Sources of Microplastics and Pathogen Vectors in Marine Environments?}

\author{
Md Abu Noman ${ }^{1,2,3}$, Jun Sun ${ }^{1,2,3 *}$ and Mohammad Belal Hossain ${ }^{4,5}$ \\ ' College of Marine Science and Technology, China University of Geosciences, Wuhan, China, ${ }^{2}$ State Key Laboratory \\ of Biogeology and Environmental Geology, China University of Geosciences, Wuhan, China, ${ }^{3}$ Research Centre for Indian \\ Ocean Ecosystem, Tianjin University of Science and Technology, Tianjin, China, ${ }^{4}$ Department of Fisheries and Marine \\ Science, Noakhali Science and Technology University, Noakhali, Bangladesh, ${ }^{5}$ School of Engineering and Built Environment, \\ Griffith University, Brisbane, QLD, Australia
}

The world has already experienced the severe adverse effects of COVID-19 at every level. When it became understood that the COVID-19 infection is spread in the community via respiratory transmission from humans, then the widespread use of plastic-made personal protective equipments (PPEs) like face masks and hand gloves tremendously increased throughout the world. Although it has reduced the spreading of virus, however, careless disposal or mismanagement of these single use PPEs has created another major concern for the environment, as plastics are a known source of environmental contamination. On one hand, they are infected with SARS-CoV-2, while on the other, they act as a carrier or vector or pathway for other pathogens or diseases, and hence can increase the degree of continuing the pandemic. Besides, there might be a chance that plastics or microplastics may be responsible for introducing new pathogenic viruses or bacteria to humankind. As such, it is clear that more research needs to be conducted to clarify this fact, and its underlying mechanisms. In this review, we briefly explored how PPE used in the COVID-19 pandemic aggravated existing microplastic pollution, how they could act as disease routes or vectors, and how they could introduce new pathogens to the terrestrial and marine environment. Addressing these questions may create awareness of plastic use, waste management, and enact relevant policy which may protect our environment and health.

Keywords: COVID-19, personal protective equipment (PPE), face masks, microplastics, plastisphere, human health

\section{INTRODUCTION}

On 11th March 2020, the World Health Organization (WHO) declared COVID-19 (SARS-CoV2) as a global pandemic (Puttaswamy et al., 2020). Various preventive measures have been taken worldwide to prevent this virus, such as lockdown and social distancing for restricting virus transmission. On an individual level, the measures are washing hands and using personal protective equipment (PPE), including face masks and gloves (Fadare and Okoffo, 2020). Among them, it is highly recommended or mandatory to wear single-use disposable surgical masks and gloves 
against the ongoing pandemic to prevent transmission of the virus. This preventive measure has led to the massive production of face masks and gloves during this pandemic (Benson et al., 2021). Polymers are the major components of PPE like masks and gloves (Fadare and Okoffo, 2020). Therefore, the massive production of PPE was responsible for introducing tonnes of plastics to the environment (Benson et al., 2021; Yousefi et al., 2021). Before the pandemic, it was estimated that global plastic production may reach 33 billion tons by the year 2050 (PlasticsEurope, 2018), but the recent addition through PPE will be a substantial contribution to that amount. However, plastics and microplastics (plastics that are smaller than $5 \mathrm{~mm}$ ) have already endangered the environment and human health. By providing a microhabitat for microorganisms, the plastic's surface could be a vector for disease transfer (Chin et al., 2020). Besides, those microplastics can be transferred to humans through the food chain and inhalation and impact human health (Cox et al., 2019; Mammo et al., 2020).

A good number of previous studies have already reported the occurrence of PPEs in the terrestrial and marine environment (Kassam, 2020; Benson et al., 2021; Dybas, 2021). Over the years, a huge amount of PPE and resulting microplastics will be added to the environment. However, it is still unknown how many microplastics are being added to the environment or, if there is any possibility that microplastics can transfer unknown pathogenic viruses or bacteria to humans from the wild environment. Based on this hypothesis, this review aims to give an idea of how and what possible amount of microplastics are being released into nature through the use of PPE during the COVID-19, the possibility of carrying other viruses in the microplastics biofilm, and describe the likelihood of introducing new virus or bacteria by vector plastics.

\section{THE PANDEMIC PRECAUTIONARY MEASURES ARE PRODUCING VAST AMOUNT OF PLASTICS/MICROPLASTICS}

Firstly, PPE, including face masks and gloves, are made of plastic polymers and have been used as precautionary measures to prevent the transmission of COVID-19. The vast production of these PPE, particularly face masks, have given rise to the tremendous amount of plastics and microplastics in the environment (Benson et al., 2021). For example, a study in South Korea revealed that if $70 \%$ of the country's urban population wear a single mask every day, at least 1,381 million microplastics fibers could be released per day in total in South Korea (Dissanayake et al., 2021). Therefore, it has increased the plastic demand attributable to medical waste by $370 \%$, while the plastic demand for the packaging industry has increased by $40 \%$. Polymers like polypropylene, polyurethane, polyacrylonitrile, polystyrene, polycarbonate, polyethylene, or polyester are the components of PPE, such as disposable face masks and gloves (Fadare and Okoffo, 2020). Non-woven materials (e.g., melt-blown fabric) are the core components of most disposable face masks; polypropylene and polyethylene are their major components. Various plastic materials such as lowdensity polyethylene, latex, vinyl, and nitrile are the components of gloves; those are highly persistent in the environment due to mechanic and chemical resistance. Like other plastic wastes, PPE-derived waste that is not treated as expected can be spread into the environment (Binda et al., 2021). Some of these materials are destined to waterways and ultimately reach the freshwater and marine environments, adding plastics into the aquatic medium. There are many reports about microplastics in the municipal wastewater and sewage effluents (Mason et al., 2016; Wang et al., 2021), and they are suspected as the most significant source of microplastics in the environment (Carr et al., 2016). Consequently, the present protection of masks mandates and human treatment procedures for COVID-19 might have added significantly to terrestrial and aquatic microplastic pollution. Besides releasing microplastics and nanoplastics, disposable face masks and other untreated equipment may release lead, cadmium, antimony, and various organic species through leaching (E\&T, 2021). Similarly, it could be one reason for SARS$\mathrm{CoV}-2$ genetic material to be in the vicinity of wastewater and the drainage of COVID-19 isolation centers and hospital (Ahmed et al., 2021), as one of the transmission routes is many face masks used worldwide by the general public, patients, and health workers (Tran et al., 2020).

\section{MICROPLASTICS COULD BE A POTENTIAL VECTOR OF PATHOGEN TRANSMISSION}

Secondly, what could the connection be between plastics and pathogens? It is known that plastics or microplastics provide new microbial niches in aquatic environments (Yang et al., 2020). Besides, there are many reports on the plastisphere community in sewage and wastewater containing human pathogenic bacteria and antibiotic resistance genes (Mason et al., 2016; Wang et al., 2021), because the surface of microplastics acts as a fertile micro-habitat for the rapid colonization of bacteria and viruses (Harrison et al., 2014; Moresco et al., 2021). However, it was hypothesized that human viruses frequently come into contact with plastics, therefore could increase the transfer of infectious viruses in the environment (Moresco et al., 2021). The possibility of the concurrent COVID-19 pandemic is much higher as the SARS-CoV-2 virus has a higher life expectancy on plastic than other surfaces like paper (Corpet, 2021), and the existence of the COVID-19 virus in water and wastewater is not insubstantial (Tran et al., 2020). However, there are no studies about the co-existence of viruses like SARS-CoV-2 in the plastisphere or their transmission route through microplastics to humans. Not only the virus transmission, but also the antibiotic resistance gene and pathogenic bacteria, might be responsible for immune dysregulation and disease in the human body (Zheng et al., 2020), and a dysfunctional immune response in COVID-19 patients can cause severe lung infection and systemic pathology (Tay et al., 2020). Therefore, is it possible that the plastics we use for the treatment unconsciously accelerate the frequency of virus 
transmission or disease? The possibility is not negligible because from our toothpaste to most remote arctic seafloor, microplastics are everywhere. According to a report, an individual consumes between 74,000 and 121,000 plastic particles per year, including exposure via inhalation, with an additional 90,000 particles for those who drink bottled water (Cox et al., 2019). As a result of their potential entry into the food chain, microplastics pose a threat to both terrestrial and aquatic life (Mammo et al., 2020).

\section{THE PLASTISPHERE MAY INTRODUCE UNKNOWN PATHOGENIC VIRUSES OR BACTERIA FROM THE WILD ENVIRONMENT}

Finally, the marine environment is the ultimate sink of microplastics and is widely distributed in beaches, seawater, sediments, and rivers (Li et al., 2020). Rivers and surface runoff are significant plastic transport pathways into the sea and carry about 80 to $94 \%$ of the total plastic load to the sea. Numerous field surveys reported the highest abundance of microplastic debris in rivers, harbor areas, tourist beaches, and nearby industrial areas (Li et al., 2020). However, human and animal pathogenic bacteria and viruses in the marine plastic microbiome are not mere. The presence of Vibrio species on microplastics or other plastics in water has been frequently reported (Mammo et al., 2020). For example, potentially human pathogens such as $V$. parahaemolyticus, $V$. mimicus, $V$. vulnificus, $V$. cholera, $V$. anguillarum, $V$. harveyi, $V$. pectinicida, and $V$. xiamenensis were confirmed in biofilms attached to plastics recovered from the Barzil and Western Mediterranean Sea (Dussud et al., 2018; Silva et al., 2019). Other potentially human pathogenic microbes such as Aeromonas, Haemophilus, Acinetobacter, Pseudomonas monteilii, Pseudomonas mendocina, and pathogenic E. coli strains were also reported from microplastics recovered from different marine environments (Mammo et al., 2020). Furthermore, SARS$\mathrm{CoV}-2$ can be released to the marine environment via human effluent, possibly present in coastal marine waters connected to sewage effluent (Mordecai and Hewson, 2020). Therefore, we hypothesize there could be a strong possibility that SARS-CoV-2 present in the plastic biofilm of that coastal area has a connection with sewage and wastewater effluent and could be a secondary route of transmission to coastal people, anglers, and tourists.

\section{REFERENCES}

Ahmed, F., Islam, M. A., Kumar, M., Hossain, M., Bhattacharya, P., Islam, M. T., et al. (2021). First detection of SARS-CoV-2 genetic material in the vicinity of COVID-19 isolation centre in Bangladesh: variation along the sewer network. Sci. Total Environ. 776:145724. doi: 10.1016/j.scitotenv.2021.14 5724

Benson, N. U., Bassey, D. E., and Palanisami, T. (2021). COVID pollution: impact of COVID-19 pandemic on global plastic waste footprint. Heliyon 7:e06343. doi: 10.1016/j.heliyon.2021.e06343

Binda, G., Bellasi, A., Spanu, D., Pozzi, A., Cavallo, D., and Bettinetti, R. (2021). Evaluating the environmental impacts of personal protective equipment use by the general population during the COVID-19 pandemic: a case study of lombardy (Northern Italy). Environments 8:33.

\section{CONCLUSION AND RECOMMENDATIONS}

Overall, based on the above-interconnected evidence, we hypothesize that humankind is in a crisis condition concerning COVID-19 and plastic pollution. Although we have to use PPE for our protection, in return, plastics produced from PPE are posing a threat to us. Therefore, to clarify whether preexisting and newly introduced microplastics in current disease treatments potentially threaten us or not, and to tackle this fact, we recommended some research directions as follows:

1. Can SARS-CoV-2 be present in the plastisphere community?

2. As the genetic material of $S A R S-C o V-2$ is present in wastewater or drain, do they exist on the plastic biofilm of that wastewater or drain?

3. Is there any existence of SARS-CoV-2 on the coastal and marine water plastic's microbiome?

4. What is the potentiality of plastic's microbiota in transferring any new contagious virus-like SARS-CoV-2 from the wild environment?

5. Reusable PPE could be a better strategy; therefore, their efficiency should be well examined.

\section{AUTHOR CONTRIBUTIONS}

MN: conceptualization, data curation, writing-original draft, and writing-review. JS: resources, funding acquisition, and supervision. MH: writing-review, editing, and formal analysis. All authors contributed to the article and approved the submitted version.

\section{FUNDING}

This research was financially supported by the National Key Research and Development Project of China (2019YFC1407805), the National Natural Science Foundation of China (41876134), and the Changjiang Scholars Program of Chinese Ministry of Education (T2014253) to JS.

Carr, S. A., Liu, J., and Tesoro, A. G. (2016). Transport and fate of microplastic particles in wastewater treatment plants. Water Res. 91, 174-182. doi: 10.1016/ j.watres.2016.01.002

Chin, A. W. H., Chu, J. T. S., Perera, M. R. A., Hui, K. P. Y., Yen, H.-L., Chan, M. C. W., et al. (2020). Stability of SARS-CoV-2 in different environmental conditions. Lancet Microbe 1:e10.

Corpet, D. E. (2021). Why does SARS-CoV-2 survive longer on plastic than on paper? Med. Hypotheses 146:110429. doi: 10.1016/j.mehy.2020.110429

Cox, K. D., Covernton, G. A., Davies, H. L., Dower, J. F., Juanes, F., and Dudas, S. E. (2019). Human consumption of microplastics. Environ. Sci. Technol. 53, 7068-7074.

Dissanayake, J., Torres-Quiroz, C., Mahato, J., and Park, J. (2021). Face masks: a looming microplastic crisis. Int. J. Environ. Res. Public Health 18:7068. doi: 10.3390/ijerph18137068 
Dussud, C., Meistertzheim, A., Conan, P., Pujo-Pay, M., George, M., Fabre, P., et al. (2018). Evidence of niche partitioning among bacteria living on plastics, organic particles and surrounding seawaters. Environ. Pollut. 236, 807-816. doi: 10.1016/j.envpol.2017.12.027

Dybas, C. L. (2021). Surgical masks on the beach. Oceanography 34, 12-14.

E\&T (2021). Disposable Masks Leak Microplastics and Other Pollutants in Water [Online]. Available online at: https://eandt.theiet.org/content/articles/2021/ 05/disposable-masks-leak-microplastics-and-other-pollutants-in-water/ [Accessed August, 20 2021].

Fadare, O. O., and Okoffo, E. D. (2020). Covid-19 face masks: a potential source of microplastic fibers in the environment. Sci. Total Environ. 737:140279. doi: 10.1016/j.scitotenv.2020.140279

Harrison, J. P., Schratzberger, M., Sapp, M., and Osborn, A. M. (2014). Rapid bacterial colonization of low-density polyethylene microplastics in coastal sediment microcosms. BMC Microbiol. 14:232. doi: 10.1186/s12866-014-0 232-4

Kassam, A. (2020). More masks than jellyfish': coronavirus waste ends up in ocean. Guardian 8. Available online at: https://www.theguardian.com/environment/ 2020/jun/08/more-masks-than-jellyfish-coronavirus-waste-ends-up-in-ocean

Li, Y., Zhang, H., and Tang, C. (2020). A review of possible pathways of marine microplastics transport in the ocean. Anthropocene Coasts 3, 6-13. doi: 10.1139/ anc-2018-0030

Mammo, F., Amoah, I., Gani, K., Pillay, L., Ratha, S., Bux, F., et al. (2020). Microplastics in the environment: interactions with microbes and chemical contaminants. Sci. Total Environ. 743:140518. doi: 10.1016/j.scitotenv.2020. 140518

Mason, S. A., Garneau, D., Sutton, R., Chu, Y., Ehmann, K., Barnes, J., et al. (2016). Microplastic pollution is widely detected in US municipal wastewater treatment plant effluent. Environ Pollut. 218, 1045-1054. doi: 10.1016/j.envpol.2016.08. 056

Mordecai, G. J., and Hewson, I. (2020). Coronaviruses in the Sea. Front. Microbiol. 11:1795. doi: 10.3389/fmicb.2020.01795

Moresco, V., Oliver, D. M., Weidmann, M., Matallana-Surget, S., and Quilliam, R. S. (2021). Survival of human enteric and respiratory viruses on plastics in soil, freshwater, and marine environments. Environ Res. 199:111367. doi: 10.1016/j.envres.2021.111367

PlasticsEurope (2018). Plastics-the Facts 2018. An Analysis of European Plastics Production, Demand and Waste Data. Brussels: Plastics Europe.

Puttaswamy, H., Gowtham, H. G., Ojha, M. D., Yadav, A., Choudhir, G., Raguraman, V., et al. (2020). In silico studies evidenced the role of structurally diverse plant secondary metabolites in reducing SARS-CoV-2 pathogenesis. Sci. Rep. 10:20584. doi: 10.1038/s41598-020-77602-0
Silva, M. M., Maldonado, G. C., Castro, R. O., De Sá Felizardo, J., Cardoso, R. P., Dos Anjos, R. M., et al. (2019). Dispersal of potentially pathogenic bacteria by plastic debris in Guanabara Bay, RJ, Brazil. Mar. Pollut. Bull. 141, 561-568. doi: 10.1016/j.marpolbul.2019.02.064

Tay, M. Z., Poh, C. M., Rénia, L., Macary, P. A., and Ng, L. F. (2020). The trinity of COVID-19: immunity, inflammation and intervention. Nat. Rev. Immunol. 20, 363-374. doi: 10.1038/s41577-020-0311-8

Tran, H. N., Le, G. T., Nguyen, D. T., Juang, R.-S., Rinklebe, J., Bhatnagar, A., et al. (2020). SARS-CoV-2 coronavirus in water and wastewater: a critical review about presence and concern. Environ. Res. 193:110265. doi: 10.1016/j.envres. 2020.110265

Wang, Z., Gao, J., Zhao, Y., Dai, H., Jia, J., and Zhang, D. (2021). Plastisphere enrich antibiotic resistance genes and potential pathogenic bacteria in sewage with pharmaceuticals. Sci. Total Environ. 768:144663. doi: 10.1016/j.scitotenv. 2020.144663

Yang, Y., Liu, W., Zhang, Z., Grossart, H. P., and Gadd, G. M. (2020). Microplastics provide new microbial niches in aquatic environments. Appl. Microbiol. Biotechnol. 104, 6501-6511. doi: 10.1007/s00253-020-10704-x

Yousefi, M., Oskoei, V., Jonidi Jafari, A., Farzadkia, M., Hasham Firooz, M., Abdollahinejad, B., et al. (2021). Municipal solid waste management during COVID-19 pandemic: effects and repercussions. Environ. Sci. Pollut. Res. 28, 32200-32209. doi: 10.1007/s11356-021-14214-9

Zheng, D., Liwinski, T., and Elinav, E. (2020). Interaction between microbiota and immunity in health and disease. Cell Res. 30, 492-506. doi: 10.1038/s41422-0200332-7

Conflict of Interest: The authors declare that the research was conducted in the absence of any commercial or financial relationships that could be construed as a potential conflict of interest.

Publisher's Note: All claims expressed in this article are solely those of the authors and do not necessarily represent those of their affiliated organizations, or those of the publisher, the editors and the reviewers. Any product that may be evaluated in this article, or claim that may be made by its manufacturer, is not guaranteed or endorsed by the publisher.

Copyright (c) 2021 Noman, Sun and Hossain. This is an open-access article distributed under the terms of the Creative Commons Attribution License (CC BY). The use, distribution or reproduction in other forums is permitted, provided the original author(s) and the copyright owner(s) are credited and that the original publication in this journal is cited, in accordance with accepted academic practice. No use, distribution or reproduction is permitted which does not comply with these terms. 